\title{
Measurement of Local Convective Heat Transfer Coefficient of an Artificialroughened Duct by Using Liquid Crystal Thermography (LCT) Technique
}

\author{
Patoda Lalit $^{1, *}$, Aharwal K. R. ${ }^{2}$, Jaiswal Sandeep ${ }^{2}$ \\ ${ }^{1}$ Engineering Service Division, Bhabha Atomic Research Centre, Visakhapatnam, India \\ ${ }^{2}$ Department of Mechanical engineering, Maulana Azad National Institute of Technology, Bhopal, India \\ *Corresponding Author: Lalit.patoda@yahoo.com
}

Copyright @ 2014 Horizon Research Publishing All rights reserved.

\begin{abstract}
The heat transfer from surfaces may in general be enhanced by increasing the heat transfer coefficient between a surface and its surroundings, and by increasing the heat transfer area of the surface, or by both. In most cases the heat transfer is concerned with the application of artificial surface roughness techniques as a turbulence promoter for convective heat transfer enhancement. To measure the transient and local convective heat transfer coefficient of an artificial roughened duct using liquid crystal thermography (LCT) technique, an experimental setup have been designed and developed. The aspect ratio of duct was maintained as three with relative roughness height ratio (e/D) of 0.13 and angle of attack is 900 for the range of Reynolds number from 7000 to 17500 .
\end{abstract}

Keywords Liquid Crystal Thermography, Local convective Heat Transfer Coefficient

\section{Introduction}

The application of heat exchanger is wide and the effective heat exchange or heat transfer is different in different applications. Internal channel cooling is employed in advanced gas turbines blade to allow high inlet temperatures so as to achieve high thrust/weight ratios and low specific fuel consumption. In case of gas turbine cooling, high heat transfer enhancement is required on the surfaces of the cooling passage so as to transfer more heat from the external surface of the air foil, which is directly exposed to the hot flowing gas. Turbulence promoters are often cast on the two opposite walls of the internal passages for heat transfer enhancement.

With the help of liquid crystal thetrmography system we can measure the temperature field of artificially roughened heat transferring surface. During the past 20-30 years or so, liquid crystals have emerged as reliable temperature and colour sensors for heat transfer, fluid flow and biomedical research, and have been applied in a number of situations to visualize the temperature distribution under complex flow fields and applications such as medical imaging, machine vision, astronomy, satellite reconnaissance, and even desktop publishing. During the same period, there has been an increasing use of desktop computers in scientific and industrial applications, first to facilitate conventional experiments and then to expand the range of possible experiments. These two new tools have come together during the past 10 years to produce a powerful new experimental technique, true-colour digital processing of liquid crystal images to yield full-field measurements of temperature, heat transfer coefficient distributions, as a judgment of food quality, and for electronic components and colour photographs, among other applications. And in case of solar air heater artificial roughness in the form of ribs is being used by the different researchers to enhance the heat transfer from the absorber plate to working fluid. The enhancement of heat transfer is greatly influenced by roughness geometry and in order to understand the actual mechanism of heat transfer temperature field measurement or velocity field measurement is required.

\section{Literature Review}

The applications of artificially roughened duct or surfaces are being used by researchers to enhance heat transfer rate from heat transferring surface to working fluid. Bruno Facchini et al. (2006) carried out experimental study concerning performances at various aspect ratios of rib roughened channels (ribs inclined at $60^{\circ}$ ), commonly employed in turbine blade cooling systems. Experimental tests were performed with transient TLC technique on a PMMA model, properly designed to reproduce large-scale cooling ducts with different aspect ratios $(\mathrm{AR}=1,2,3)$. To validate the test model and the data acquisition and reduction procedure, a smooth channel was initially studied and relative results were found in good agreement with common 
correlations for heat transfer and pressure losses. Stasiek et al. (1997) carried out a new experimental technique, in this case true-colour image processing of liquid crystal patterns, allows new approaches to old problems and at the same time opens up new areas of research.

Hwang et al. (1993) investigated the fully developed flow in channels roughened with three rib shapes, namely square, semicircular and triangular cross section. The results showed that the three types of rib channels had comparable thermal performance, but the square-ribbed geometry is the most likely the one to yield hot spots behind the rib. Bruno Facchini et al. (2006) carried out experimental study concerning performances at various aspect ratios of rib roughened channels (ribs inclined at $60^{\circ}$ ), commonly employed in turbine blade cooling systems. Experimental tests were performed with transient TLC technique on a PMMA model, properly designed to reproduce large-scale cooling ducts with different aspect ratios $(\mathrm{AR}=1,2,3)$. To validate the test model and the data acquisition and reduction procedure, a smooth channel was initially studied and relative results were found in good agreement with common correlations for heat transfer and pressure losses. Stasiek et al. (1997) carried out a new experimental technique, in this case true-colour image processing of liquid crystal patterns, allows new approaches to old problems and at the same time opens up new areas of research.

Image processed data makes available quantitative, full-field information about the distribution of temperature and heat transfer coefficient which will undoubtedly encourage the study of situations which have been, until now, too complex to consider.

Based on literature revive it is observe that artificially roughness place an important role in the enhancement of heat transfer from heat transferring surface to the working fluid. Many investigators have used the artificial roughness in different ways for the enhancement of heat transfer and they have measured the average Convective Heat Transfer Coefficient, however in order to understand the actual mechanism of heat transfer measurement of Transient and Local Convective Heat Transfer Coefficient is required. Therefore for the present work the following objectives were taken:

1) Design and Development of an Experimental Setup to Measure the Transient and Local convective Heat Transfer Coefficient of an artificial roughened duct Using Liquid crystal thermography (LCT) technique.

2) Data collection and taking images with respect to temperature for smooth and roughened duct.

3) Analysis of Local convective heat transfer coefficient and pressure loss.

\subsection{Range of Operating Parameters}

For the present investigation based on the literature the range of operating and roughness parameters has been decided as follows:

Table 1. Roughness parameters are used

\begin{tabular}{|c|c|}
\hline Parameters & Values \\
\hline Test Length & $1480 \mathrm{~mm}$ \\
\hline Thickness of acrylic Plate & $12 \mathrm{~mm}$ \\
\hline Angle of attack & 900 \\
\hline Hydraulic Diameter & $88.88 \mathrm{~mm}$ \\
\hline Relative roughness pitch (p/e) & 9.0 \\
\hline Relative roughness height (e/Dh) & 0.13 \\
\hline Roughness height (e) & $12 \mathrm{~mm}$ \\
\hline Channel Aspect ratio (W/H) & 3.0 \\
\hline Reynolds Number $(\mathrm{Re})$ & -17500 \\
\hline
\end{tabular}

\section{Experimental Setup Details and Procedure}

For the present work an artificially roughened rectangular duct has been designed and developed having length, width and height in the order of 1480,171 and $60 \mathrm{~mm}$ respectively. The Aspect Ratio $(\mathrm{W} / \mathrm{H})$ of duct was maintained as 3:1. A short entrance length $\left(L / D_{h}=7.2\right)$ was chosen because for a roughened duct the thermally fully developed flow is established in a short length 2-3 hydraulic diameter.

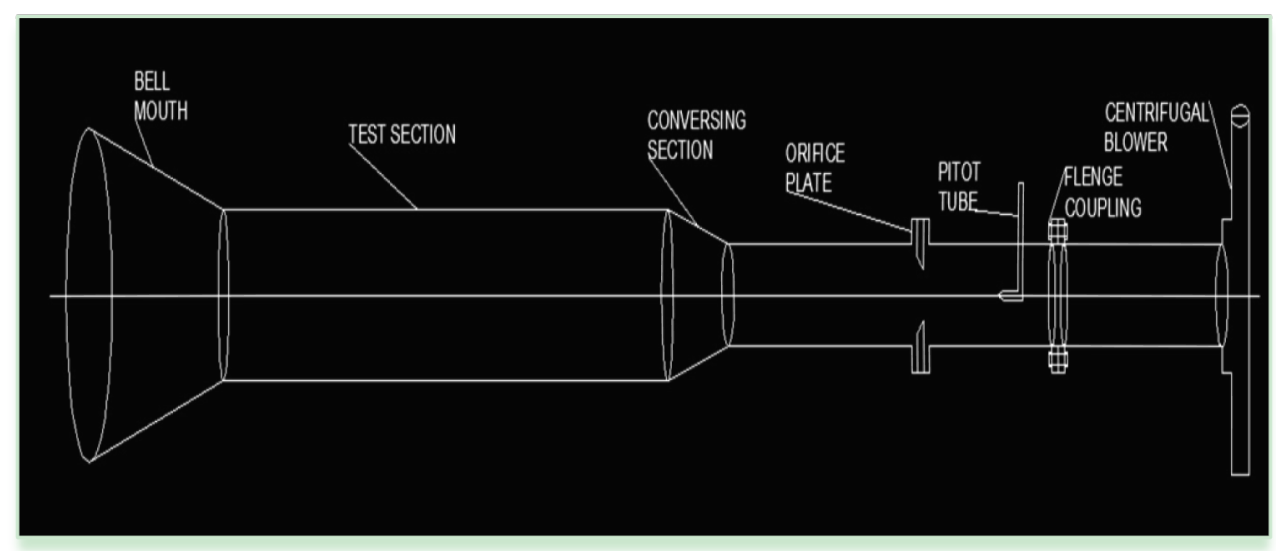

Figure 1. Schematic Diagram of Experimental Setup 
For the turbulent flow regime, ASHRAE standard 93-77 (1977) recommends entry and exit lengths were $(5 \sqrt{ } \mathrm{WH})$ and $(2.5 \sqrt{ } \mathrm{WH})$ respectively. In order to maintain the stream line flow inside the duct a bell mouth section is having 3:1 contracting cone and made by flexible plywood of length $720 \mathrm{~mm}$ was used at the inlet of the duct. .The test section consists of smooth Acrylic sheet. The flow is measured with the help of an orifice meter. The temperature of any point of test section can be easily recorded by Digital camera and with the help of data logger. The micro manometer was used for measurement of pressure loss across the test section in a duct.

\section{Calculation of Local Convective Heat Transfer Coefficient}

The local surface temperature on the target plate is thus represented by the classical one-dimensional response of a semi-infinite medium to the sudden step application of a fluid flow at temperature To. Solving 1-D transient heat conduction equation one can obtain the value of local convective heat transfer coefficient.

$$
\begin{aligned}
& \frac{T(x, t)-T i}{T \infty-T i}=\operatorname{erfc}\left(\frac{x}{2 \sqrt{\alpha t}}\right)-\exp \left(\frac{h x}{k}+\frac{h^{2} \alpha \mathrm{t}}{k^{2}}\right)\left[\operatorname { e r f c } \left(\frac{x}{2 \sqrt{\alpha t}}+\right.\right. \\
& \text { hath) }
\end{aligned}
$$

\section{Where}

Ti = Initial Temperature, $T_{\infty}=$ Flowing Air Temperature, $T(x, t)=$ Temperature at distance $x$ from the leading edge at a given time instant, $x=$ Distance from the leading edge, $k=$ Thermal Conductivity of acrylic sheet, $\alpha=$ Thermal Diffusivity of acrylic sheet, $h=$ Local Convective Heat Transfer Coefficient.

To determine the local heat transfer coefficient $h$ on the smooth/ribbed-surface, the change in temperature of the surface is measured in terms of the colour change recorded with the help of camera. The colour of the coated-surface turning into green was determined according to the calibration test of temperature change of the liquid crystal. The corresponding time, $t$, to reach the temperature for any surface is measured by using the image processing system.

\section{Results and Discussion}

The results and discussion are summarized in two different ways as first one is image analysis which will give qualitative analysis of local heat transfer mechanism and other is the quantitative analysis which will gives us values of local convective heat transfer coefficient and pressure loss on the basis of recorded data.

\subsection{Image Analysis}

In order to correlate the variation of temperature (convective heat transfer coefficient) with the colour change of liquid crystal sheet, the temperature of the liquid crystal sheet was measured with the help of digital thermometer and it is observed that as the temperature is decreased, the colour of liquid crystal sheet changes accordingly.

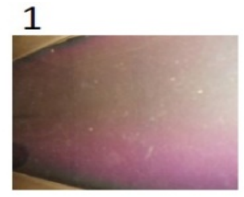

4

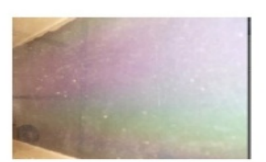

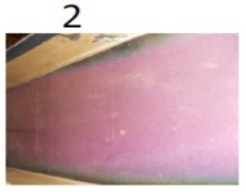

5

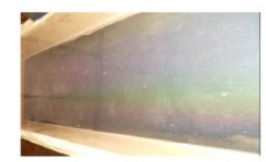

3

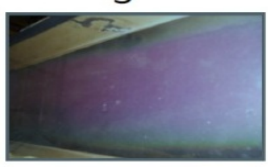

6

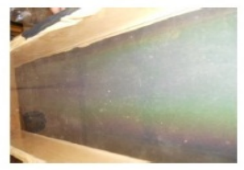

Figure 2. Images of smooth surface captured with the help of camera with respect to temperature variation.
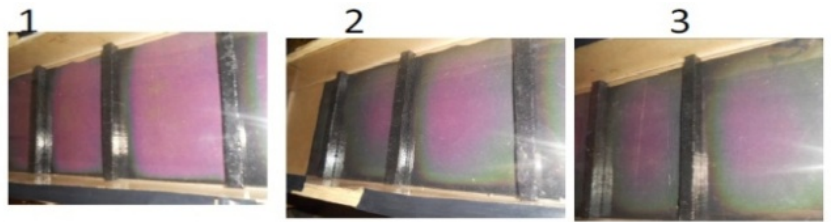

4

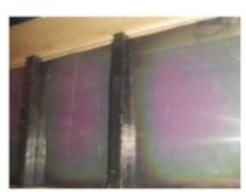

5

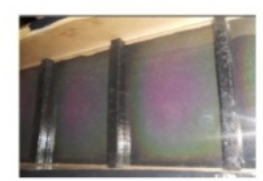

6

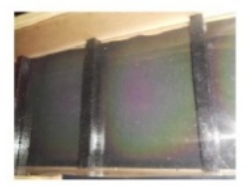

Figure.3. Images of rib roughened surface captured with the help of camera with respect to temperature variation

Figure 2 and 3 shows the variation colour with respect to time for smooth and roughened surfaces respectively. This variation of colour with respect to time has been used for the analysis of local convective heat transfer coefficient. For the quantitative analysis of the local convective heat transfer coefficient of artificially roughened duct has been measured for the selected operating and roughness parameters. The local convective heat transfer coefficient of smooth and artificially roughened has been calculated by using equation (1) and the results are shown in Table $2 \& 3$ respectively.

Table 2 shows the value of local convective heat transfer coefficient for smooth surface at a distance of $450 \mathrm{~mm}$ from the entrance section. For this particular set of data the inlet temperature was kept as $50^{\circ} \mathrm{C}$ and Reynolds number was maintained as 17493 corresponding to the pressure loss across the test section is $14 \mathrm{~Pa}$. The duration of time was maintained as 90 seconds.

The variation of temperature and local convective heat transfer coefficient as a function of time has also been seen and it is shown in Fig.4. From this Fig it is seen that the convective heat transfer coefficient is decreases with respect to time and hence the temperature of the surface is increasing with respect to time. This may be due to fact that means initially the rate of heat transfer is 
Table 2. observations for smooth duct

\begin{tabular}{|c|c|c|c|c|}
\hline Sr. No. & $\begin{array}{c}\text { Position } \\
(\mathrm{x}, \mathrm{mm})\end{array}$ & $\begin{array}{c}\text { Time } \\
(\text { Seconds })\end{array}$ & $\begin{array}{c}\text { Temperature } \\
\left({ }^{\circ} \mathrm{C}\right)\end{array}$ & $\begin{array}{c}\text { Local Convective Heat Transfer } \\
\text { Coefficient }\left(\mathrm{W} / \mathrm{m}^{2} /{ }^{\circ} \mathrm{C}\right)\end{array}$ \\
\hline 01 & 450 & 30 & 33.4 & 52.0 \\
\hline 02 & 450 & 60 & 35.2 & 49.8 \\
\hline 03 & 450 & 90 & 36.6 & 47.9 \\
\hline 04 & 450 & 120 & 37.5 & 46.5 \\
\hline
\end{tabular}

Table 3. observation for artificial roughened duct

\begin{tabular}{|c|c|c|c|c|}
\hline $\begin{array}{c}\text { Sr. } \\
\text { No. }\end{array}$ & $\begin{array}{c}\text { Position } \\
(\mathrm{x}, \mathrm{mm})\end{array}$ & Time (Seconds) & $\begin{array}{c}\text { Temperature } \\
\left({ }^{\circ} \mathrm{C}\right)\end{array}$ & $\begin{array}{c}\text { Local Convective Heat Transfer } \\
\text { Coefficient }\left(\mathrm{W} / \mathrm{m} 2 /{ }^{\circ} \mathrm{C}\right)\end{array}$ \\
\hline 01 & 450 & 30 & 37.1 & 63.2 \\
\hline 02 & 450 & 60 & 39.3 & 61.0 \\
\hline 03 & 450 & 90 & 40.9 & 59.1 \\
\hline 04 & 450 & 120 & 42.2 & 57.8 \\
\hline
\end{tabular}

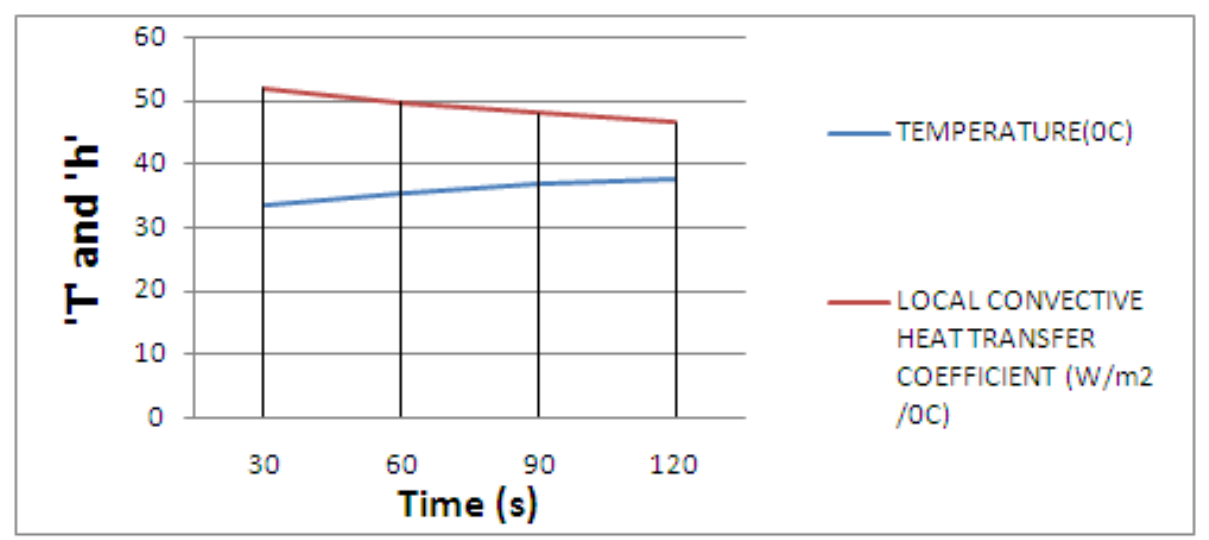

Figure 4. Variation in Temperature and Local Convective Heat Transfer Coefficient in case of smooth surface

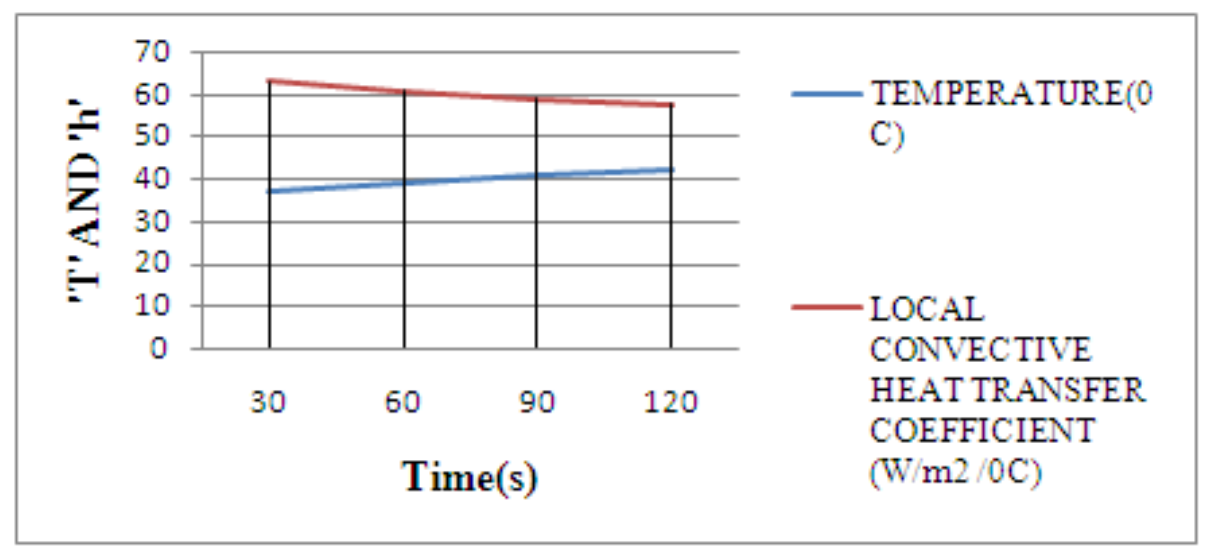

Figure 5. Variation in Temperature and Local Convective Heat Transfer Coefficient in case of artificial roughened duct

more but after few seconds of time the rate of heat transfer is less than previous value and we observed that initially at a given point the temperature is less but after few seconds of time the temperature is more than previous value. The range of convective heat transfer coefficient is varies from 46.5 to $52 \mathrm{~W} / \mathrm{m}^{2} \mathrm{~K}$.

Table 3 shows the value of local convective heat transfer coefficient for smooth surface at a distance of $450 \mathrm{~mm}$ from the entrance section. For this particular set of data the inlet temperature was kept as $50^{\circ} \mathrm{C}$ and Reynolds number was maintained as 17493 corresponding to the pressure loss across the test section is $24 \mathrm{~Pa}$. The duration of time was maintained as 90 seconds.

The variation of temperature and local convective heat transfer coefficient as a function of time has also been seen and it is shown in Fig.5. From this Fig. it is seen that the convective heat transfer coefficient is decreases with respect to time and hence the temperature of the surface is increasing 
with respect to time. This may be due to fact that means initially the rate of heat transfer is more but after few seconds of time the rate of heat transfer is less than previous value and we observed that initially at a given point the temperature is less but after few seconds of time the temperature is more than previous value. The range of convective heat transfer coefficient is varies from 57.8 to $62.3 \mathrm{~W} / \mathrm{m}^{2} \mathrm{~K}$. It is further seen that the value of local convective heat transfer coefficient is higher for artificially roughened duct compare to that of the smooth duct because the roughness increase the number of re-attachment points which enhance the heat transfer.

\section{Conclusions}

Based on the above observations the following conclusions may be drawn from the present work.

In the present study, actual mechanism of heat transfer of smooth and artificially roughened surface has been studied using liquid crystal sheet which shows different colours corresponds to different temperature at different instant of time.

1) At a given point for unsteady state in smooth and roughened, as the time increases the temperature at that point increase but value of local convective heat transfer coefficient decreases, that means initially the rate of heat transfer is more but after few seconds of time the rate of heat transfer is less than previous value and we observed that initially at a given point the temperature is less but after few seconds of time the temperature is more than previous value.

2) Local convective heat transfer coefficient in artificially roughened duct is more than that of smooth duct and also pressure loss is more in artificially roughened duct.

3) It is observed that local convective heat transfer coefficient range and temperature range are varies with the distance from leading edge and time.

4) From the observation recorded the mechanism of separation, reattachment and eddies formation can be visualized clearly, which is very essential mechanism of heat transfer.

5) It is also observed that the Reynolds number is directly proportional to mass flow rate or velocity or pressure loss in the test section.

\section{REFERENCES}

[1] Han, J.C., (1984) Heat Transfer and Friction in Channels with Two Opposite Rib Roughened Walls, ASME J. Heat Transfer, Vol 6, pp. 774-781.

[2] C. Camci, K. Kim, S.A. Hippensteele, (1992) A new hue capturing technique for the quantitative interpretation of liquid cry stalimages used in convective heat transfer studies, ASME J. Turbomach. 114 765-775.

[3] Miin, L.T., and Hwang, J.T., (1993), Effect of Ridge Shapes on Turbulent Heat Transfer and Friction in a Rectangular Channel, Int. J. Heat \& Mass Transfer, Vol. 30, pp. 931-940.

[4] Stasiek J. (1997) Thermochromic liquid crystals and true colour image processing in heat transfer and fluid-flow research, Heat Mass Transf. 33, 27-29,

[5] Diego Cavallero, Giovanni Tanda, (2001) An experimental investigation of forced convection heat transfer in channels with rib tabulators by means of liquid crystal thermography, Genova, Italy 16145.

[6] P.R. Chandra, C.R. Alexander, J.C. Han, (2003) Heat transfer and friction behaviour in rectangular channels with varying number of ribbed walls, International Journal of Heat and Mass Transfer 46, 481-495.

[7] Cengel Y.A. (2003) Heat transfer, a Practical approach, Tata McGraw-Hill publications, second addition in SI Units.

[8] K.R. Aharwal, B.K. Gandhi, J.S. Saini (2008) Experimental investigation on heat-transfer enhancement due to a gap in an inclined continuous rib arrangement in a rectangular duct of solar air heater, Renewable Energy, Volume 33, Issue 4, Pages 585-596.

[9] Bruno Facchini, Luca Innocenti, Marco Surace, (2006) Design criteria for ribbed channels: Experimental investigation and theoretical analysis, International Journal of Heat and Mass Transfer 49, 3130-3141.

[10] Sachdeva R.C .(2010) Fundamental of Engineering Heat \& mass transfer, New Age International publications, fourth addition in SI Units.

[11] ASHARE Standard (1977), 93-97 Method of testing to determine the thermal performance of solar collectors. 